\title{
Brahms, Developing Variation, and the Schoenberg Critical Tradition
}

\author{
WALTER FRISCH
}

In 1946 Robert Maynard Hutchins, Chancellor of the University of Chicago, sought Arnold Schoenberg's advice on the creation and organization of a music department. Schoenberg recommended, as one of several possibilities, "a clean-cut Musicological Department," whose sole function should be research. He graciously provided Hutchins with "Some Problems for the Department," a list of "a few ... subjects with which classes could become busy." As might be expected, Schoenberg included mainly compositional and analytical topics, such as "methods of transition" and a "systematic cataloguing of features of rhythm." He also proposed a subject suggestively called "developing variation."

Although Schoenberg discussed developing variation only sporadically-and often aph-

\footnotetext{
${ }^{1}$ Arnold Schoenberg, Letters, ed. Erwin Stein, trans. E. Wilkins and E. Kaiser (New York, 1965), pp. 240-42.

$0148-2076 / 82 / 010215+18 \$ 00.50$ (C) 1982 by The Regents of the University of California.
}

oristically-in his critical writings, he clearly considered it one of the most important compositional principles of Western music from the common-practice era to his own day. It is thus worthwhile to gather and examine his scattered remarks in order to form a clear picture of the term and the concept. In one essay Schoenberg explains:

Music of the homophonic melodic style of composition, that is, music with a main theme, accompanied by and based on harmony, produces its material by, as I call it, developing variation. This means that variation of the features of a basic unit produces all the thematic formulations which provide for fluency, contrasts, variety, logic and unity on the one hand, and character, mood, expression, and every needed differentiation, on the other handthus elaborating the idea of the piece. ${ }^{2}$

${ }^{2}$ Schoenberg, Style and Idea: Selected Writings of Arnold Schoenberg, ed. Leonard Stein (New York, 1975), p. 397. All further page references in section I of this article are to the Stein edition. 
Elsewhere Schoenberg defines the procedure more polemically. He offers the blunt postulate, "Whatever happens in a piece of music is nothing but the endless reshaping of a basic shape," and then elaborates:

Or, in other words, there is nothing in a piece of music but what comes from the theme, springs from it and can be traced back to it; put still more severely, nothing but the theme itself. Or, all the shapes appearing in a piece of music are foreseen in the "theme." I say a piece of music is a picture-book consisting of a series of shapes, which for all their variety still (a) cohere with one another, [and] (b) are presented as variations (in keeping with the idea) of a basic shape, the various characters and forms arising from the fact that variation is carried out in a number of different ways (p. 290).

It is clear that Schoenberg is not discussing variation form, as in a theme and a series of discrete variations, but a more flexible compositional procedure whereby the different elements of a basic idea or shape-what he called a Grundgestalt-are successively modified. Indeed, Schoenberg contrasts traditional variation form with the technique of developing variation. Of the former he notes: ". . in primordial specimens, sets of variations serve rather the virtuoso who wants to be brilliant through his technique. In such variations there is seldom any other development than velocity and no other change than the figuration of the instrumental style." But "artistically superior compositions" (including the more sophisticated variation sets) are generated "through 'developing variations' of basic features of the theme and its motive ... producing thematic material for forms of all sizes: the melodies, main and subordinate themes, transitions, codettas, elaborations, etc., with all the necessary contrasts" (pp. 165-66).

Schoenberg's essays do not spell out the ways in which the theme can be varied-I return to that topic below-but they do begin to suggest how he viewed the historical evolution of developing variation. He claims that J.S. Bach originated the procedure, which was then taken up and refined by the Viennese classicists (pp. 115, 118). We are given no specific examples of how Bach employed the technique, but are told that he created "the art of producing everything from one thing and of relating figures by transformation" (p. 173). In one well-known example Schoenberg seeks to demonstrate more concretely how "the method of developing variation" was used by the preeminent Viennese classicist, Beethoven; the second subject in the first movement of the Fifth Symphony is derived "from a reinterpretation of the two main notes [of the first subject], $\mathrm{E}_{b}$ and $\mathrm{F}$, as tonic and dominant of $\mathrm{E}_{b}$ major" (p. 164). This is, unfortunately, not one of Schoenberg's more persuasive analyses. ${ }^{3} \mathrm{He}$ was more successful at-and clearly more interested in-demonstrating how developing variation informs the music of Brahms, who, he felt, brought the procedure to its most advanced state.

In "Criteria for the Evaluation of Music," in Style and Idea, Schoenberg contrasts Brahms's compositional techniques with those of Wagner. The latter, "in order to make his themes suitable for memorability, had to use sequences and semi-sequences, that is, unvaried or only slightly varied repetitions differing in nothing essential from their first appearances, except that they are exactly transposed to other degrees" (p. 129). Schoenberg gives two examples from Tristan, the first seven measures of the Prelude and the two measures of Isolde's command to Brangäne in Act I, scene 2, "Befehlen liess dem Eigenholde." In each a brief phrase is repeated sequentially (though not exactly). Dismissing this technique as "primitive" and "inferior," Schoenberg points admiringly to Brahms, who avoided exact repetition and "repeated phrases, motives, and other structural ingredients of themes only in varied forms, if possible in the form of ...developing variation."

\footnotetext{
${ }^{3}$ Treating only a few measures of music, the analysis is too brief and too superficial to persuade us of the significance of developing variation in shaping Beethoven's movement as a whole. Furthermore, it misconstrues the first theme; as Schenker demonstrated, and as basic musical perception tells us, the "two main notes" are not $E_{b}$ and F, but the pitches on the two analogous downbeats, $\mathrm{Eb}$ and $\mathrm{D}$. Schenker's compelling analysis treats $\mathrm{E}_{b}-\mathrm{D}$ as the basic "two-note motive" of the movement. See Der Tonwille 1 (1921), 27-37; trans. Elliot Forbes and F. J. Adams, Jr., in Beethoven: Symphony No. 5 in C Minor, ed. Elliot Forbes, Norton Critical Score (New York, 1971), pp. 164-82.
} 
In this essay Schoenberg does not analyze any music by Brahms, but he does so on several other occasions. In a radio talk of 1931 he appeals to the example of a late Brahms theme in order to defend the theme of his own Orchestral Variations, op. 31, against charges of incomprehensibility. "New music is never beautiful on first acquaintance," Schoenberg claims. "The reason is simply this: one can only like what one remembers; and with all new music that is very difficult. ${ }^{\prime \prime}$ The great popular composers constructed their melodies by "repeating every little phrase often enough for it to impress itself on the listener." After quoting the first part of Strauss's Blue Danube Waltz-numbering from one to seven the parallel repetitions of the simple fourmeasure phrase-Schoenberg observes:

But a stricter style of composition must do without such convenient resources. It demands that nothing be repeated without promoting the development of the music, and that can only happen by way of far-reaching variations.

Here is a theme that develops rapidly. You are certainly expecting me to quote something modern and extreme, but you are wrong: It is the opening of Brahms's F-major Cello Sonata [op. 99]:

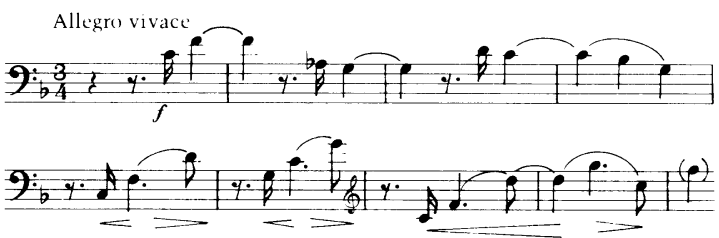

Young listeners will probably be unaware that at the time of Brahms's death this sonata was still very unpopular and was considered indigestible.... At that time the unusual rhythm within this ${ }_{4}^{3}$, the syncopations which give the impression that the third phrase is in ${ }_{4}^{4}$ :

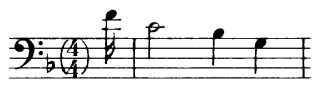

${ }^{4}$ Schoenberg, "The Orchestral Variations, Op. 31: A Radio Talk," given over the Frankfurt Radio in 1931, printed in The Score 27 (1960), 28. The original German is "Vortrag über op. 31," Stil und Gedanke: Aufsätze zur Musik, ed. Ivan Vojtech (Frankfurt, 1976), 256-57. This talk does not appear in the English Style and Idea. and the unusual intervals, the ninths contained in this phrase [m. 5], made it difficult to grasp. I felt all this myself, so I know how seriously it must be taken!

To make matters worse, the theme develops too quickly, and its motivic evolution is very difficult for the ear to trace, without the help of the written page. It is only there that one sees that the opening fourth is inverted into a fifth;

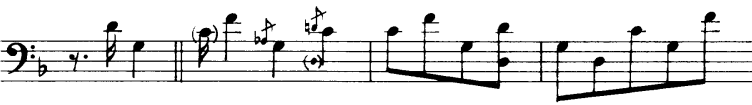

but this is hard for the ear to grasp, if only because the initial phrasing in two-note groups then switches to groups of three:

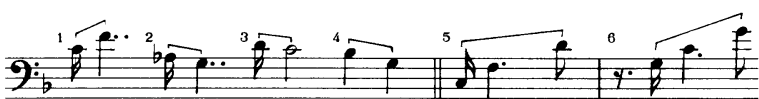

So those who did not understand at the time were right (pp. 28-30).

In its penultimate paragraph Schoenberg's analysis develops almost as elliptically as the theme itself. We do not learn precisely where or how the opening fourth is inverted to a fifth: the D-G figure never actually appears in the initial rhythm, as Schoenberg notates it; nor is it easy to discern among his parentheses and grace-notes.

At any rate, the actual intervallic development of the motive seems less significant /and harder for the ear to grasp/ than its rhythmic evolution, as displayed in Schoenberg's last musical example, where we see how Brahms progressively transforms the two-note figure. In $\mathrm{m}$. 4 the "upbeat" and the longer note equalize into two quarter notes (or we might hear $\mathrm{m} .4$ as an extension, by two quarter notes, of the initial figure); then in $\mathrm{m} .5$ the original motive sprouts an afterbeat. The developmental process reaches its climax in $\mathrm{mm}$. 8-9 when this figure too is extended.

Schoenberg might have noted that this rapid, explosive motivic growth is contained within an outwardly regular nine-measure
WALTER FRISCH Brahms and Developing Variation 
phrase, cleanly divided into a four-measure antecedent and a five (four, plus an extension)measure consequent. The metric "stretch" of Schoenberg's proposed ${ }_{4}^{4}$ measure at the end of the antecedent is perfectly complemented by what we could interpret as a ${ }_{4}^{5}$ measure across mm. 7-8 (ex. 1):

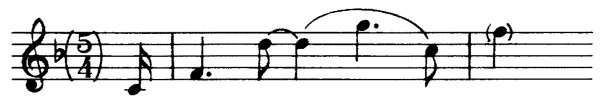

Example 1

By slightly refining Schoenberg's analysis, then, we can begin to see just how he understood developing variation in Brahms: the building of a theme by rapid development of a brief motive, with the concomitant creation of metrical fluidity or ambiguity - the whole process reined in by a phrase structure that on the higher level is essentially symmetrical.

In "Brahms the Progressive," perhaps his most famous essay, Schoenberg reveals the same procedures at work in other Brahms themes. Like the radio talk, this essay (also given first as a radio talk, in 1933) has a polemical intent: to prove that Brahms, so often branded pejoratively as "the classicist, the academician," was, in fact, "a great innovator in the realm of musical language." ${ }^{\prime 5}$ Much of the demonstration involves brief examples of Brahms's asymmetrical phrase structurescombinations of phrases of differing lengths and numbers of measures not divisible by eight, four, or two. But Schoenberg gives a more extended, and more persuasive, account of how two Brahms themes are generated by the process of developing variation: those from the Andante of the A-Minor String Quartet, op. 51 , no. 2, and from the third of the Four Serious Songs, "O Tod." 6

The quartet theme, Schoenberg notes, "contains exclusively motive forms which can be explained as derivatives of the interval of a

5Schoenberg, "Brahms the Progressive," Style and Idea, $\mathrm{p}$. 401.

${ }^{6}$ For a discussion and expansion of Schoenberg's analysis of the song, see pp. 270-82 of my Ph.D. dissertation, Brahms's Sonata Structures and the Principle of Developing Variation (University of California, Berkeley, 1981). second" (see ex. 2). The multiple staves in Schoenberg's example do not represent any hierarchy of structural levels; they serve only to display the numerous motive forms which Brahms develops from the basic second, labelled $a$. As Schoenberg explains:

$b$ then is the inversion upward [sic] of $a$;

$c$ is $a+b$;

$d$ is part of $c$;

$e$ is $b+b$, descending seconds, comprising a fourth;

$f$ is the interval of a fourth, abstracted from $e$, in inversion (p. 431).

Schoenberg anticipates criticism of this kind of motivic analysis, noting that skeptics "might reason that steps of a second or even fractions of a scale are present in every theme without constituting the thematic material." But he defends himself by pointing out that his second example, "O Tod," displays "a similar secret" based on another single interval, a third, and that the metrical-rhythmic development of a motive is (as we saw in op. 99) just as important as the purely intervallic processes-indeed, that they cannot be separated.

As Carl Dahlhaus has suggested in his commentary on Schoenberg's analysis, the two halves of Brahms's theme (mm. 1-5 and 5-8) function much like an antecedent and consequent, although in fact they have little overt correspondence besides their Dreigliedrigkeit, their division into three phrases each. ${ }^{7}$ Schoenberg attempts to show how these six phrases evolve independently of the notated ${ }_{4}^{4}$ meter. The first three phrases, and the last, each occupy one and a half measures, the fourth and fifth a single measure. After the first phrase, this design wreaks havoc with the written bar line:

The first phrase ends practically on the first beat of measure 2. In order to appreciate fully the artistic value of the second phrase's metrical shift, one must realize that even some of the great composers, Brahms's predecessors, might have continued as in [example 3], placing the second phrase in the third measure (p. 435).

"Carl Dahlhaus, "Musikalische Prosa," Schönberg und Andere: Gesammelte Aufsätze zur Neuen Musik (Mainz, 1978), p. 137. 


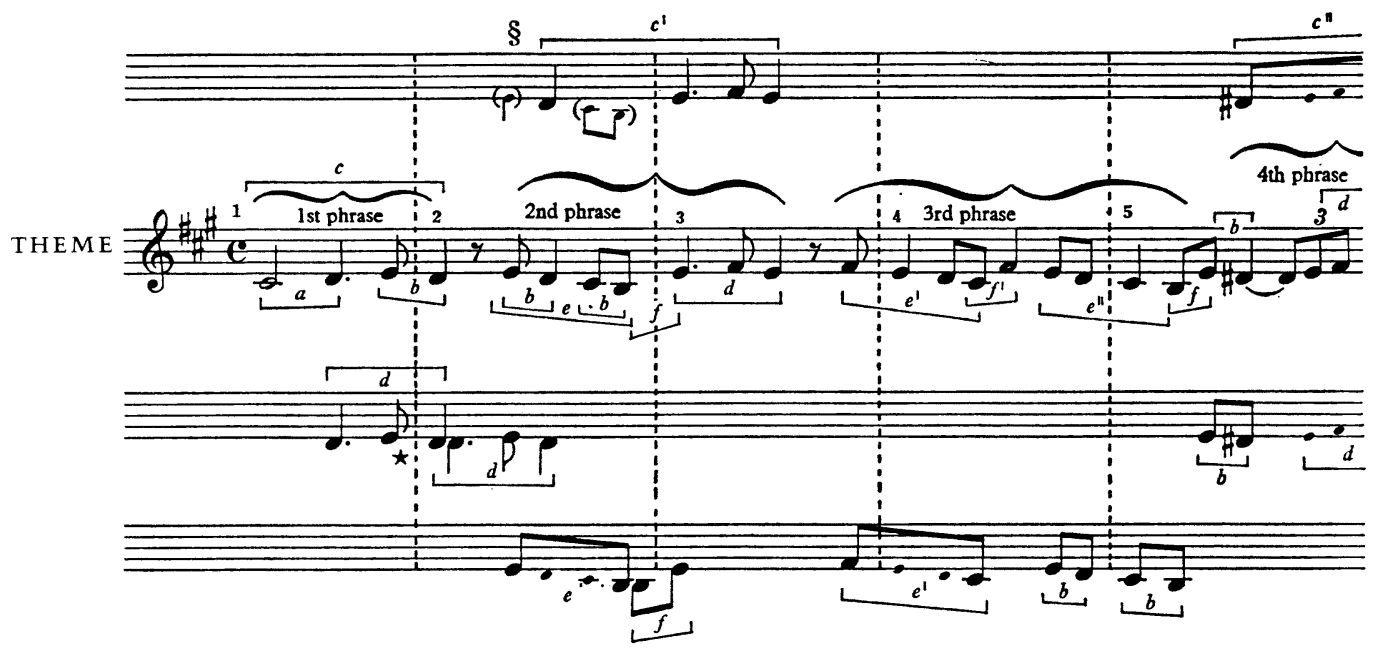

WALTER FRISCH

Brahms and

Developing

Variation

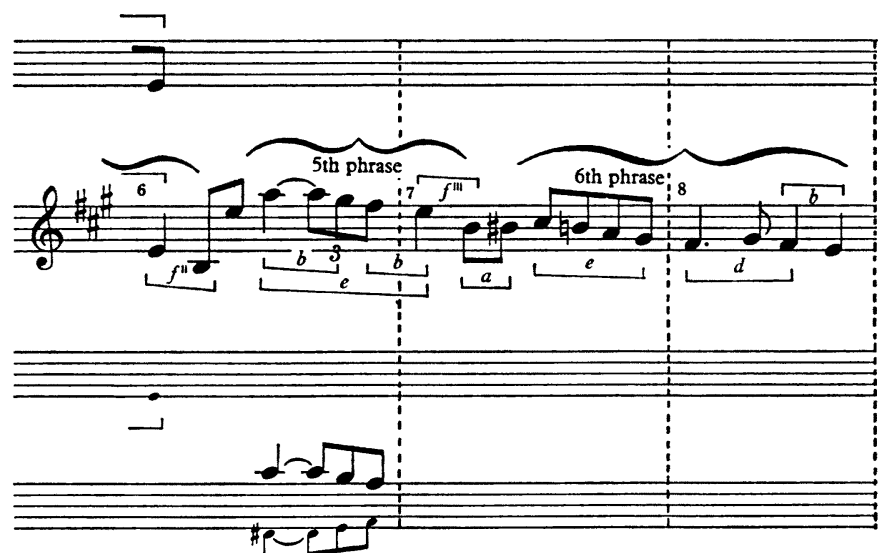

Example 2: Schoenberg's analysis of Brahms's String Quartet, op. 51, no. 2

(Examples 2-8 and 10 are reproduced by permission of St. Martin's Press, Inc., Macmillan \& Co. Ltd.)

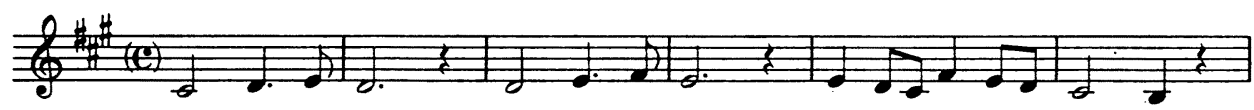

Example 3: Schoenberg's rewriting of the Brahms theme

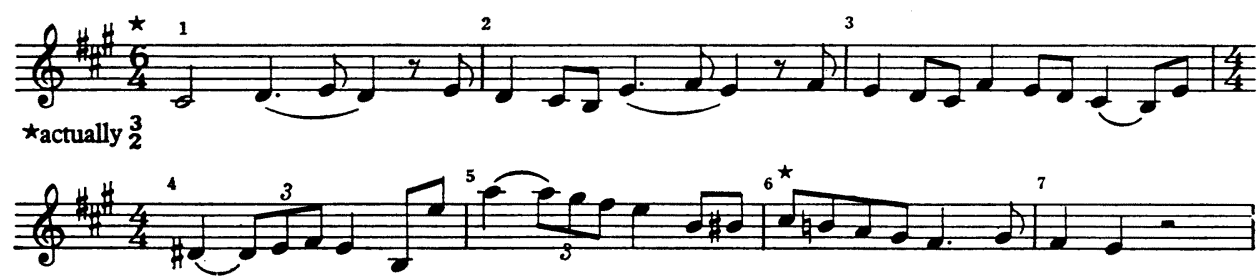

Example 4: Schoenberg's rebarring of the Brahms theme 
But Brahms eschews any such symmetry, preferring to let his theme expand more freely.

In his next example (ex. 4), Schoenberg preserves Brahms's phrases intact, but rebars them in order to have analogous accents appear in the same part of a measure. The result is that the first three phrases fall into ${ }_{2}^{3}$, the fourth and fifth in ${ }_{4}^{4}$. But, as Schoenberg indicates with the asterisk above m. 6, the last phrase is not adequately represented by this plan, "if all the preceding phrases had their main accents placed on first beats."

Dahlhaus correctly observes that Schoenberg's rebarring obscures the manner in which Brahms shifts the metrical weight within phrases, a process which is partly the result of the harmonic Stufen. ${ }^{8}$ The first phrase begins on a downbeat with a note of the tonic A-major chord; the D on the third beat, part of a diminished ii chord, is appropriately on a weak part of the measure. But the $\mathrm{E}$ in the second phrase, analogous to the earlier $\mathrm{D}$, returns us to the tonic and (in Brahms's notation) is thus in its proper place on the downbeat of $\mathrm{m}$. 3 . Schoenberg ultimately agrees that Brahms's notation is the most sensible, since it contains the motivic development within a rational eight measures: "In Brahms's notation these subcutaneous beauties are accommodated within eight measures; and if eight measures constitute an aesthetic principle, it is preserved here in spite of the great freedom of construction" (pp. 435-36).

As in the op. 99 theme, then, Brahms retains here an outwardly regular structure within which motives expand and develop quite freely. The manipulation of a theme's internal rhythm and meter is one of Brahms's most powerful tools of developing variation. ${ }^{9}$

Schoenberg characterized themes like those of opp. 51 and 99 as "musical prose," that is, music which does not fall into regular, predefined or predictable patterns. The Blue Danube theme, with its repeated symmetrical phrases, would be "musical verse." Musical

${ }^{8}$ Dahlhaus, "Musikalische Prosa," p. 137

${ }^{9}$ Metrical and rhythmic aspects of developing variation in Brahms's music are treated in Frisch, Brahms's Sonata Structures, especially with regard to the Piano Quintet in F Minor, op. 34 (pp. 144-60), and the Third Symphony, op. 90 (pp. 239-53). prose, however, is "a direct and straightforward presentation of ideas, without any patchwork, without mere padding and empty repetitions" (p. 415). Developing variation and musical prose are, in a sense, two different ways of describing the same process. Developing variation-the principle according to which ideas are continuously varied-provides the means, the grammar by which the musical prose is created.

I have quoted at length from both the radio talk and "Brahms the Progressive" in part because Schoenberg's ideas seem intimately linked with his crusty prose style-and thus resist paraphrase-but also because the two analyses reveal the nature and the true importance of developing variation in Brahms. To summarize: by developing variation Schoenberg means the construction of a theme by the continuous modification of one or more features (intervals, rhythms) of a basic idea, according to certain recognized procedures, such as inversion, fragmentation, extension, and displacement. Schoenberg values developing variation as a compositional principle because it can prevent obvious and hence monotonous repetition. And in his view Brahms's music stands as its most advanced manifestation in the common-practice era, for Brahms "develops" his motives almost at once and dispenses with small-scale rhythmic or metrical symmetry, thereby creating genuine musical prose. Schoenberg himself adopted these procedures in his early compositions, thus carrying developing variation into the twentieth century. ${ }^{10}$

\section{II}

Schoenberg's analyses generally serve a polemical function and are thus highly idiosyncratic and selective. He concentrates only on the more progressive aspects of motivic development in Brahms (and other) themes. But fortunately Schoenberg did leave a more systematic, even-handed account of de-

\footnotetext{
${ }^{10}$ See Frisch, Brahms's Sonata Structures, Chapter 7 (pp. 283-310). I have not been able to consult the recent Ph.D. dissertation by Michael Musgrave, Brahms and Schoenberg: A Study of Schoenberg's Response to Brahms's Music As Revealed in his Didactic Writings and Selected Early Compositions (University of London, 1980), which touches on this topic and on others relevant to the present study.
} 
Rhythmic changes

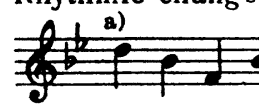

b)

Addition of ancillary notes

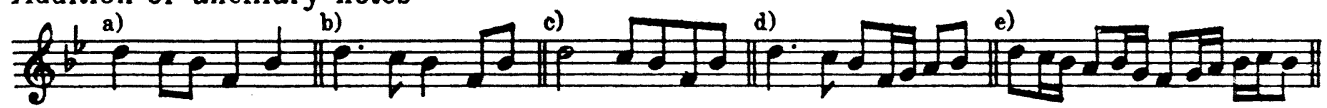

Reduction, omission, condensation

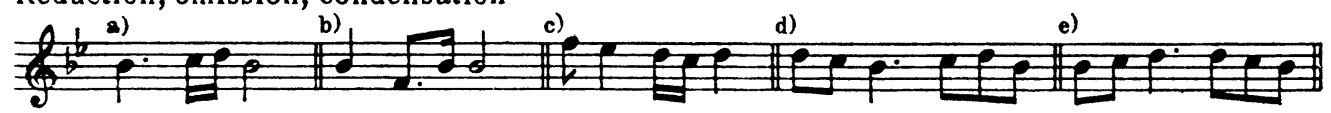

Addition of upbeats, repetition of features

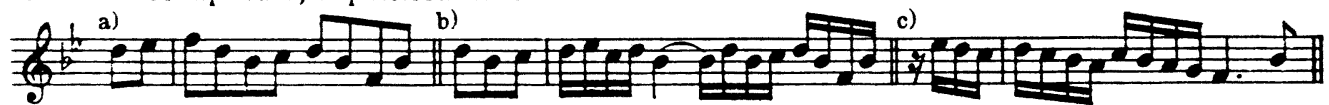

Shift to other beats

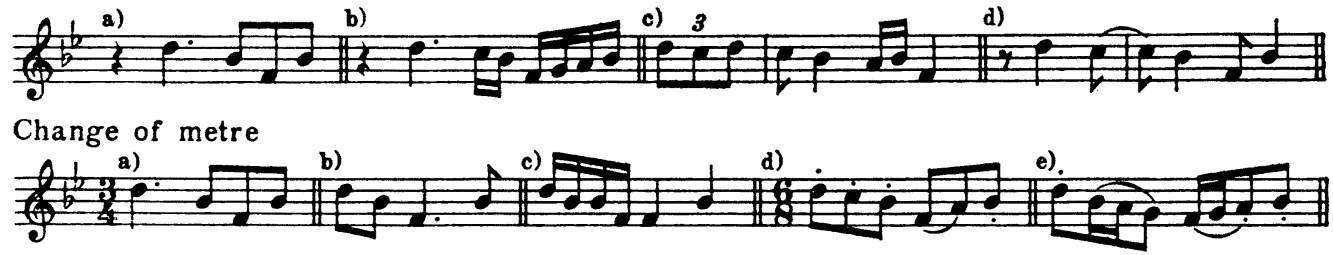

Example 5: Developing variations of a motive based on a broken chord
WALTER FRISCH

Brahms and

Developing

Variation veloping variation, of the basic premises behind what often seem to be impulsive critical or analytical judgements. This discussion is found not in essays or radio talks, but (logically enough) in a textbook. In Fundamentals of Musical Composition, written during the years 1937-48, Schoenberg wears a very different hat than in Style and Idea, that of the practical didact explaining carefully the procedures of developing variation to the student composer. The composer is not the sole beneficiary of the meticulous instruction, however, for it proves equally useful to the analyst at the other end of the creative process (although it has rarely, if ever, been employed in this way).

The composer's basic tool is the motive, whose features are "intervals and rhythms, combined to produce a memorable shape or contour."11 Schoenberg stresses that the coher-

${ }^{11}$ Schoenberg, Fundamentals of Musical Composition, ed. Gerald Strang and Leonard Stein (New York, 1967), p. 8. Further page references in section II are to this edition. For a helpful summary and synthesis of Schoenberg's theories of motivic development, see David Epstein, Beyond Orpheus: Studies in Musical Structure (Cambridge, Mass., 1979), Appendix A ("Schoenberg's Studies of Motives, Motive-Forms, and Developing Variations"), pp. 207-10. ence of a composition, our "final impression," depends not on the motive's initial form, but on its "treatment and development." The composition grows by the continuous repetition of a motive, a repetition which can be exact or modified (and thus developed):

Exact repetitions preserve all features and relationships. Transpositions to a different degree, inversions, retrogrades, diminutions and augmentations are exact repetitions. .. .

Modified repetitions are created through variation....

Some variations, however, are merely local "variants," and have little or no influence on the continuation.

Variation, it must be remembered, is repetition in which some features are changed and the rest preserved.

All the features of rhythm, interval, harmony and contour are subject to various alterations . . . but such changes must not produce a motive-form too foreign to the basic motive (p. 9). ${ }^{12}$

In a set of made-up musical examples entitled "Developing variations of a motive based on a broken chord" (ex. 5) Schoenberg demonstrates

${ }^{12}$ It is significant that despite their mutual disagreement on most theoretical issues, Schoenberg and (the early) 

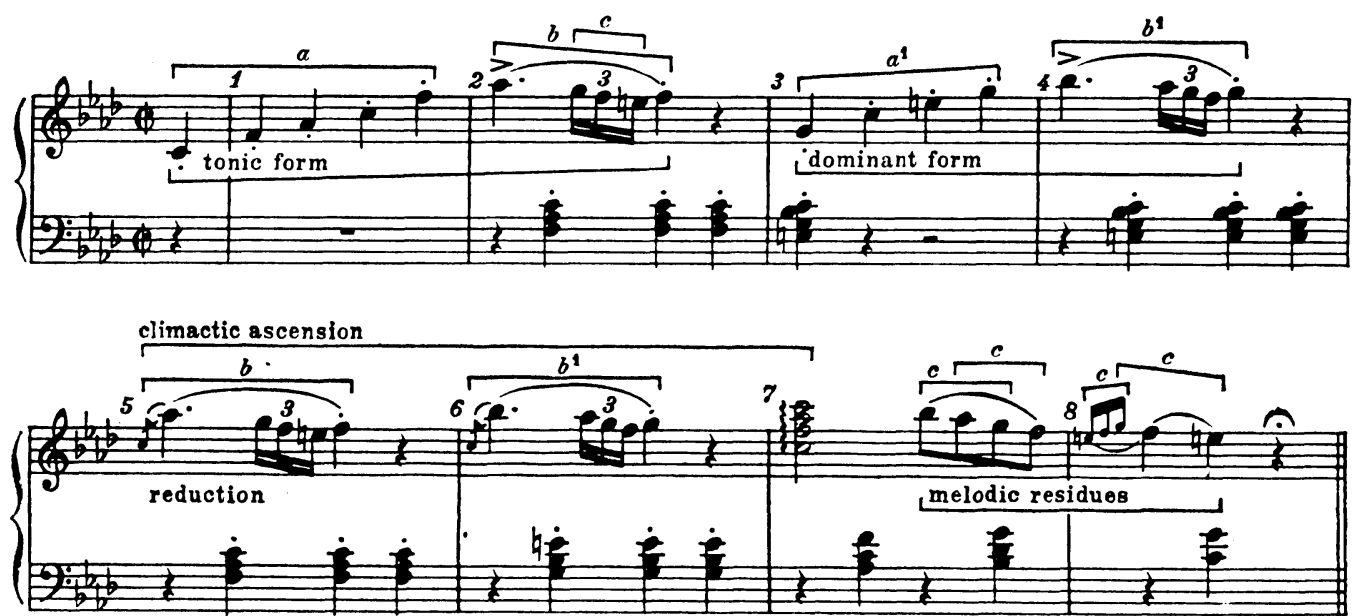

Example 6: Schoenberg's analysis of Beethoven's Sonata, op. 2, no. 1

just how these features (rhythm, meter, interval, contour, etc.) can be modified. These motive forms do not "develop" successively from one another, of course, but simply constitute different individual alternatives of development. ${ }^{13}$ However, Schoenberg soon advances to a higher structural level at which continuous elaboration does take place.

After demonstrating how to build single phrases by connecting the varied motive forms (see his Chapter IV), Schoenberg moves on to

Schenker concur on the importance of repetition in generating musical form. In his Harmonielehre (1906) Schenker claims that a motive is actually defined or created by repetition: "Only by repetition can a series of tones be characterized as something definite... Repetition is thus the basis of music as an art." (Harmony, ed. Oswald Jonas, trans. E. M. Borghese [Cambridge, 1973], p. 4). Schoenberg underlined this very passage with red crayon in his own copy of Schenker's book and in the margin added some comments of approval. See Jonathan M. Dunsby, "Schoenberg and the Writings of Schenker," Journal of the Arnold Schoenberg Institute 2 (1977), 28.

${ }^{13}$ It should be clear by now that Schoenberg uses the terms "developing" and "development" (and "variation") not as formal designations-as in a development section-but in a more general sense. Schoenberg feels "development" is a misnomer for the central segment of a sonata form: "It suggests elaboration and growth which rarely occur. The thematic elaboration and modulatory 'working out' (Durchführung) produce some variation, and place the musical elements in different contexts, but seldom lead to the 'development' of anything new." (Fundamentals, p. 200). the musical sentence, which "not only makes a statement of an idea, but at once starts a kind of development." He explains:

The practice form will consist, in simpler cases, of eight measures, of which the first four comprise a phrase and its repetition. The technique to be applied in the continuation is a kind of development, comparable in some respects to the condensing technique of "liquidation." Development implies not only growth, augmentation, extension and expansion, but also condensation and intensification (p. 58).

The locus classicus for such an eightmeasure sentence is perhaps the opening theme of Beethoven's F-Minor Piano Sonata, op. 2, no. 1, which Schoenberg parses as in example 6 . The first two-measure phrase is repeated sequentially on the dominant; the continuation, an indivisible four-measure unit (mm. 5-8), "reduces" the initial phrase by separating off and developing motives $\mathrm{b}$ and $\mathrm{c}$. Beethoven also intensifies the harmonic rhythm, which accelerates from one harmony per two measures (in $\mathrm{mm}$. 1-4), to one per measure (in mm. 5-6), finally to two harmonies in $\mathrm{m} .7$.

Schoenberg includes numerous other examples from the classical and romantic literature, but his own "model" sentences prove the most illuminating. He provides no clue as to their musical idiom; nor has anyone, to my knowledge, commented on their stylistic pro- 


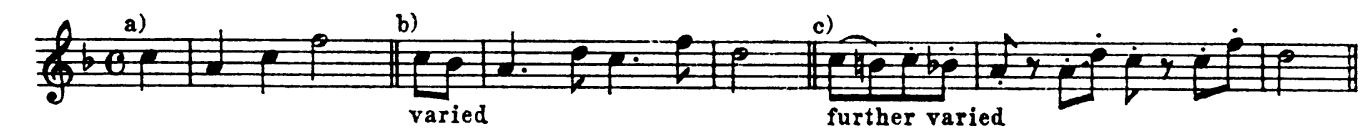

WALTER FRISCH

Brahms and

Developing
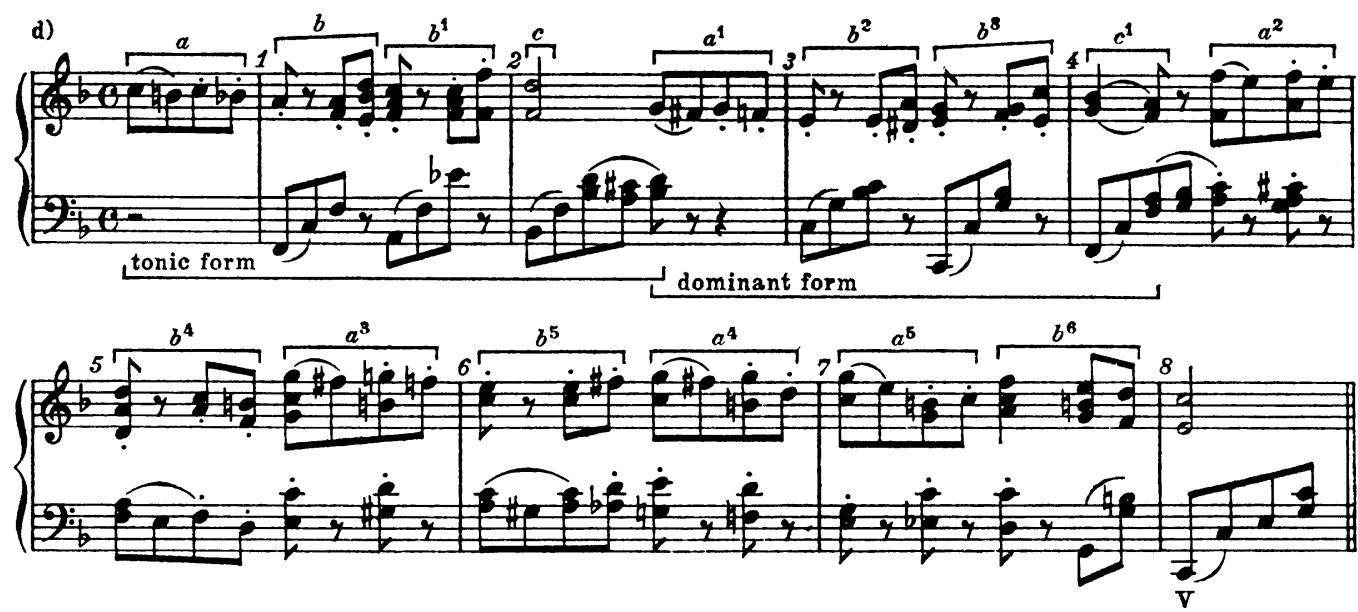

Example 7: Schoenberg's "classical" sentence

gression. But when studied in sequence Schoenberg's examples 54 and 55 (given as exx. 7 and 8) comprise-better than any possible verbal description-an extraordinary capsule history of developing variation from the classical composers to Brahms.

On the first staff of ex. 7 Schoenberg shows the three-stage process $(a, b, c)$ of constructing a theme from a broken-chord motive similar to the one examined above. From this (d) he composes a full eight-measure sentence according to the "practice form," that is, a two-measure phrase, its varied repetition, and a fourmeasure continuation or "development" (ex. 7). The repetition (mm. 2-4) is essentially a sequential reiteration, on the dominant, of the original phrase: the accompaniment pattern and the succession of motive forms $(a, b, c)$ remain constant. In the continuation (mm. 5-8), as Schoenberg remarks, the motive forms still retain their original order but are now "reduced" or "condensed": the cadential c is eliminated, and at each occurrence $b$ is heard only once, not twice as it was in $\mathrm{mm} .1$ and 3 . Schoenberg's procedure thus closely follows that of Beethoven's F-Minor Sonata. Indeed, although Schoenberg does not specify any musical style, the clearly articulated phrase structure and relatively simple motivic develop- ment of this example clearly point to a late classical idiom, perhaps to that of Hummel, Weber, or Schubert.

After offering two alternative continuation sections (new versions of mm. 5-8), Schoenberg recomposes the entire sentence with the same motives, but in a different meter. (This is given as example 8 . The proportions of the original are doubled, so that the whole sentence is now 16 measures long instead of 8 . The initial phrase has 4 measures, the repetition 4 , and the continuation or development 8.) Again Schoenberg fails to indicate the style, but our eyes and ears could, I think, take it for none other than Brahms's. The piano writing is perhaps the most obviously Brahmsian element-in particular the broken-chord figuration of the right hand in $\mathrm{mm} .3$ and 7-13. (See, for example, the piano part from the Vivace of the A-Major Violin Sonata, op. 100, which Schoenberg has quoted earlier in his book, p. 57.) But more revealing are the structural features on which Schoenberg himself comments.

The continuation phrase (mm. 9-16) "begins with a transposition $\left[\mathrm{c}^{2}\right]$ of that feature which ended the preceding phrase $\left(\mathrm{c}^{1}, \mathrm{~m} .8\right)$ and associates it with $b$ in the form used in $\mathrm{m} .3$ and 7 [i.e., the broken-chord figuration]" (p. 

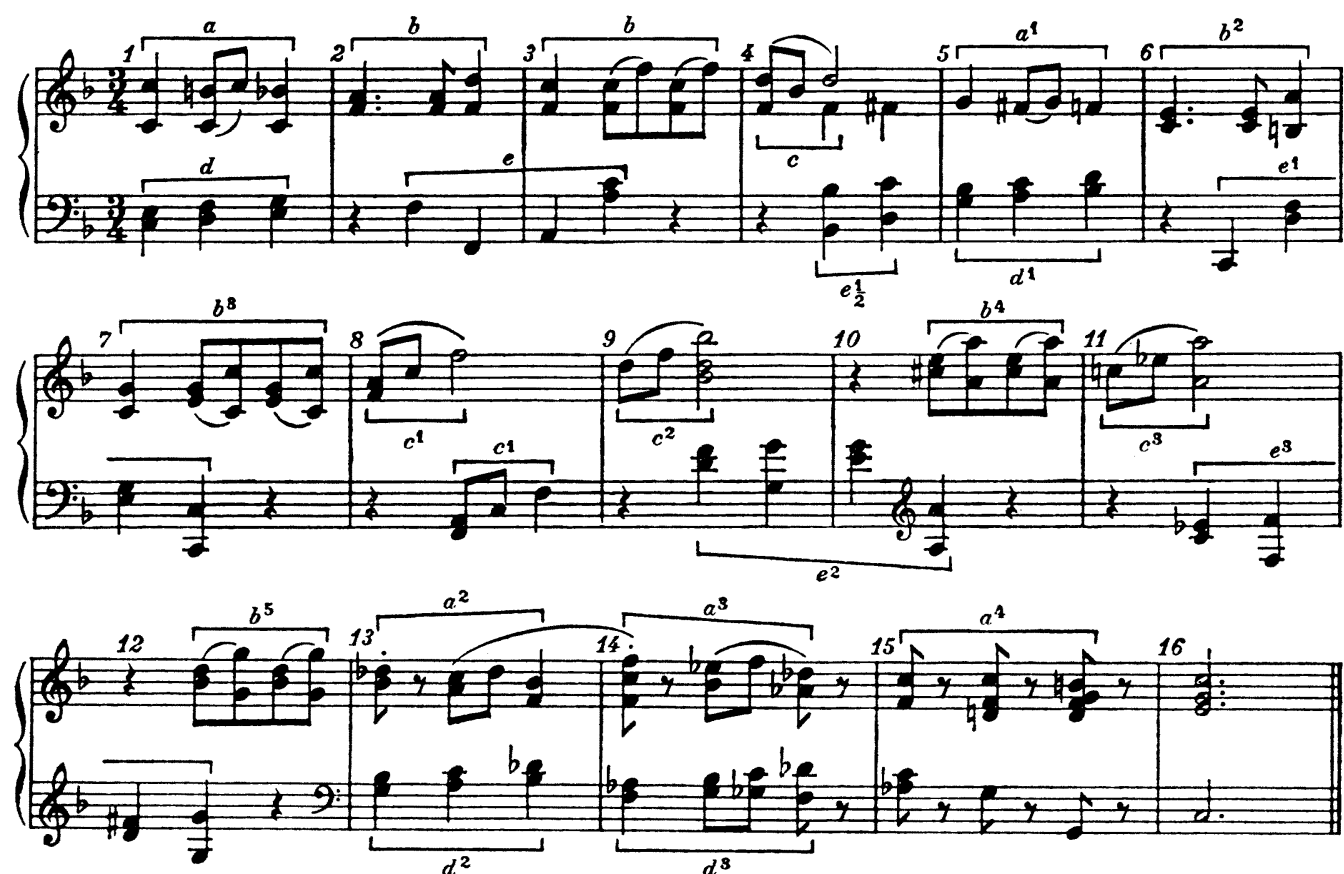

Example 8: Schoenberg's "Brahmsian" sentence

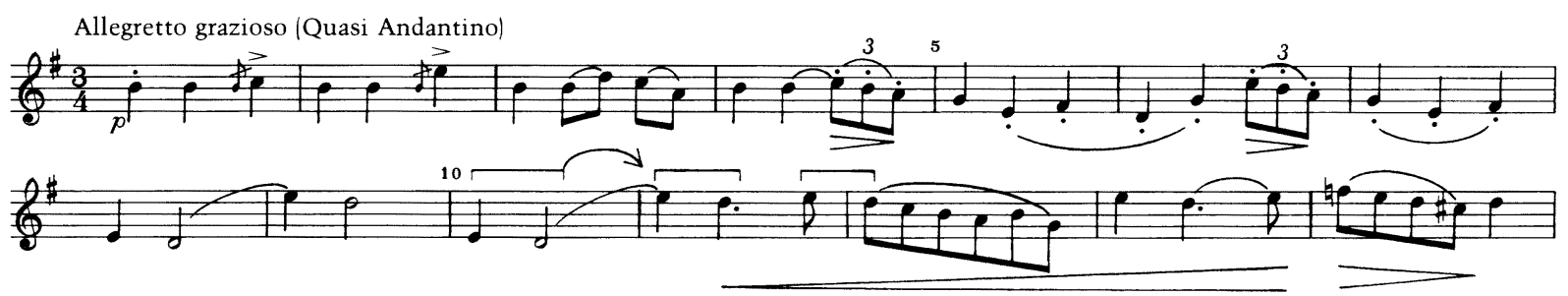

Example 9: Brahms, Second Symphony, op. 73

60). ${ }^{14}$ In Schoenberg's earlier, "classical" sentence $c$ served only as a cadential figure to close off the first two phrases. But here the cadential $\mathrm{c}^{1}$ generates the first motive form of the next phrase, $\mathrm{c}^{2}(\mathrm{~m}$. 9). This technique, by which a "new" idea evolves spontaneously from a preceding one, is a distinctly Brahmsian fingerprint, which Schenker called Knüpftechnik, or linkage technique. ${ }^{15}$

${ }^{14}$ As printed on p. 65 of Fundamentals, the "Brahmsian" example has no motive $\mathrm{c}^{1}$. The motives of $\mathrm{m} .8$ are labeled $\mathrm{c}^{2}$, that of $\mathrm{m} .9 \mathrm{c}^{3}$, and that of $\mathrm{m} .11 \mathrm{c}^{4}$. This is undoubtedly an error and has been corrected in ex. 8, where I have lowered the c superscripts by one to bring them into accord with Schoenberg's discussion of the example.

${ }^{15}$ Schenker, Harmony, pp. 9-10 and fn. 10 (p. 10). For fur-
One well-known example is the theme from the Allegretto of the Second Symphony (ex. 9), in which the two-note cadential figure, E-D, of mm. 8-10, is taken over to initiate the next phrase in $\mathrm{m}$. 11. The pitches remain the same, but the harmonic support is altered. In "Brahms the Progressive" Schoenberg provides an exquisite example of Brahms's Knüpftechnik on a smaller scale. In the Andante from

ther discussion and examples of Schenker's concept, see Sylvan Kalib, Thirteen Essays from the Three Yearbooks Das Meisterwerk in der Musik (Ph.D. diss., Northwestern, 1973|, I, 89-92. See also Oswald Jonas, Einführung in die Lehre Heinrich Schenkers: Das Wesen des musikalischen Kunstwerkes, rev. edn. (Vienna, 1972), pp. 6-9. Jonas remarks on Brahms's predilection for the Knüpftechnik. 


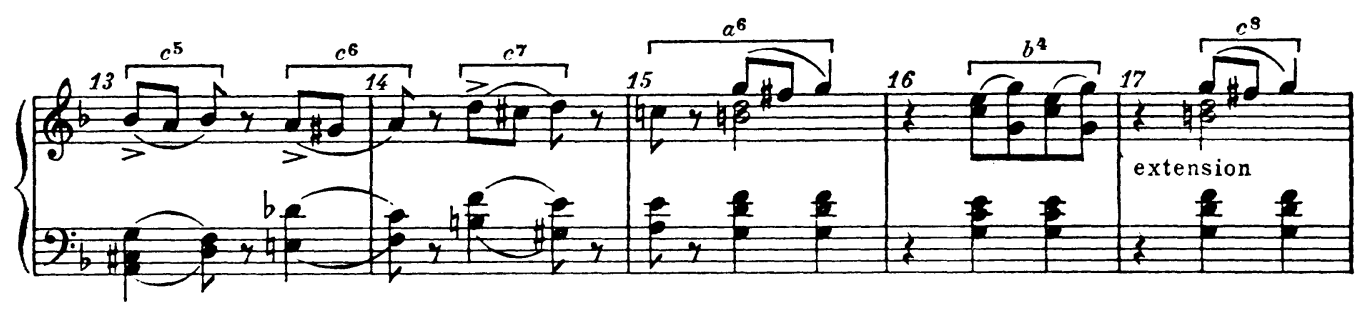

WALTER FRISCH

Brahms and

Developing

Variation

Example 10: Schoenberg's continuation of Example 8

the String Quartet (see ex. 2, p. 219) the tail of each "phrase" immediately generates the succeeding phrase. Observe, for example, how motive form $b$ ends the first and initiates the second. Or, as Schoenberg indicates on the third stave, motive form $d$ overlaps-literally "knüpfs" - the two phrases. Its third note, D, serves both as conclusion and beginning.

To return to Schoenberg's "Brahmsian" sentence in Fundamentals (ex. 8): the juncture between phrases displays not only the Knüpftechnik but also a typically Brahmsian moment of ambiguity. When in m. 8 the left hand breaks in upon the right hand's cadential $\mathrm{c}^{1}$ with a statement of the same motive, we become uncertain of where the phrase ends. The ambiguity is then compounded in $\mathrm{m}$. 9 as the right hand gives out $\mathrm{c}^{2}$, which we initially take for a further echo of $\mathrm{c}^{1}$, although it in fact begins the next phrase. The subdominant harmony at m. 9 enhances the ambiguity, for it is not the conventional starting point of a continuation phrase: neither Schoenberg's "classical" sentence (ex. 7) nor any of his other examples begins its "development" on IV.

The Allegretto from Brahms's Second Symphony (ex. 9) contains a very similar ambiguity at the juncture between phrases. An E-D cadential motive appears first in $\mathrm{m} .8$ and is echoed an octave higher in $\mathrm{m}$. 9. It returns in m. 10 to the original register, and appears to be echoed once again in $\mathrm{m} .11$; but this last echo in fact initiates the new phrase. Precisely as in the Schoenberg example, the successive motivic repetitions make us uncertain where one phrase ends and the other begins. Here, too, the harmony obscures the phrase juncture. The first phrase concludes on a dominant seventh $\left(\mathrm{D}^{7}, \mathrm{~mm} .8-10\right)$; the first bar of the second phrase then resolves that chord to another dominant seventh $\left(\mathrm{G}^{7}\right.$, or $\left.\mathrm{V}^{7} / \mathrm{IV}\right)$. The tonic arrives only on the third beat of the measure.

The motivic nature of Schoenberg's accompaniment in ex. 8 also evokes Brahms. In the "classical" example (ex. 7) the left-hand part consists mostly of conventional figuration, which attracts little attention /except in $\mathrm{mm}$. 2,5 , and 6 where the bass imitates motive a). But in the "Brahmsian" sentence the rhythmic patterns-to which Schoenberg gives labels of their own, $\mathrm{d}$ and e-undergo a developmental process. Schoenberg comments, "Observe also the treatment of the motive of the accompaniment, e, which . . . is shifted from the weak to the strong measures in $\mathrm{mm} .9-10^{\prime \prime}$ (p. 60). That is, e moves from its initial position across mm. 2-3 of a four-measure phrase to a new position within the first two measures $\left(\mathrm{e}^{2}, \mathrm{~mm}\right.$. 9-10 of the example). ${ }^{16}$

Schoenberg goes on to provide two alternative continuations for the "Brahmsian" sentence. The second (see ex. 10) betrays a further characteristic device-Brahms's beloved hemiola, which here serves to develop and vary motives c (mm. 13-14) and b (mm. 19-20).

In these examples, then, Schoenberg has demonstrated how Brahms's style of developing variation evolves from and extends the practices of classical composers. In Brahms motivic development becomes more intense and pervasive. It permeates all parts of the tex-

\footnotetext{
${ }^{16}$ One could take the opposite point of view from Schoenberg and claim that $e$ is shifted from a strong to a weak measure. Initially, the stress of $\mathrm{e}$-that is, its coincidence with a downbeat, and not its first note-falls on a strong measure (m. 3). At m. 10, then, that stress falls on the weak measures of a four-measure phrase. The weak-strong decision is complicated, however, because the first phrase begins on a weak harmony, $\mathrm{V}$, which resolves to the tonic in m. 2, normally the weak measure of a four-measure phrase. All these ambiguities could be considered eminently Brahmsian in spirit.
} 


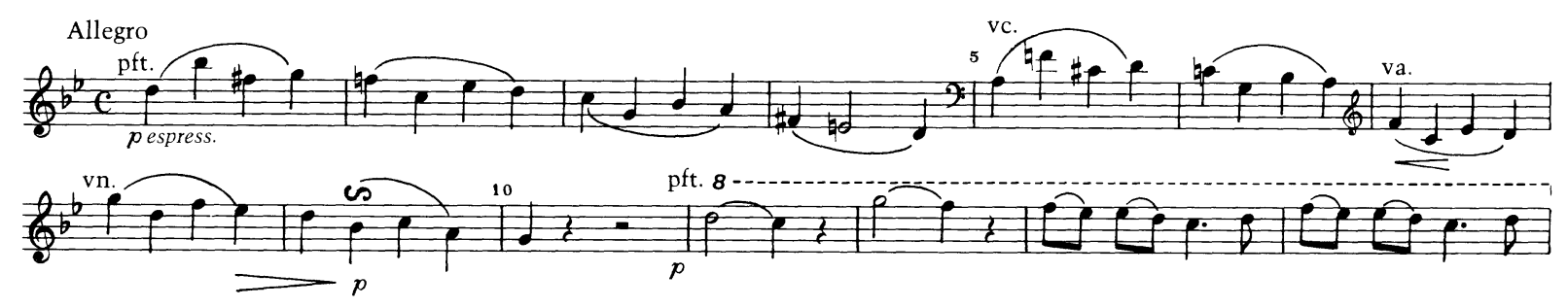

Example 11: Brahms, Piano Quartet, op. 25

ture and even begins to break down or obscure the phrase structure, as in the ambiguity created at the juncture between the halves of the sentence. Motivic development can also affect the metrical framework, as in the hemiola, where a ${ }_{2}^{3}$ pattern is superimposed over the notated ${ }_{4}^{3}$. Thus, although Schoenberg's intention in Fundamentals is ostensibly to give the student composer several ways of developing motive forms, he has in fact provided a perceptive account-in purely musical terms-of how different would be the results were Brahms to handle the same formal structure and the same motivic material as one of his classical forbears.

\section{III}

Although one can, as I have tried to do, extract an historical (or style-historical) account of developing variation from Schoenberg's writings, his approach is clearly more theoretical than chronological. Indeed, his unsubstantiated suggestion that developing variation originated with Bach and then "made possible the style of the Viennese classicists" must strike us as inadequate and simplistic. But by expanding on Schoenberg's concepts Carl Dahlhaus has recently advanced a more sophisticated and compelling view. In his essay "Issues in Composition," Dahlhaus argues that developing variation emerged in the later nineteenth century as one response to the central "problem" composers faced-how to create large forms from very concise thematic material. ${ }^{17}$

\footnotetext{
${ }^{17}$ Carl Dahlhaus, "Issues in Composition," Between Romanticism and Modernism: Four Studies in the Music of the Later Nineteenth Century, trans. Mary Whittall, California Studies in 19th-Century Music, no. 1 (Berkeley and Los Angeles, 1980).
}

After Beethoven, Dahlhaus claims, "form fell into a state of one-sided dependence on the musical idea," that is, on the initial motive or theme. "Musical form now presented itself primarily (though by no means exclusively) as a consequence drawn from thematic ideas, not as a system of formal relations" (p. 42). And because composers felt a strong pressure to be "original," they tended to do away with conventional material or mere filler. As a result, the actual thematic ideas became very concise.

Building on the distinction Schoenberg makes in "Criteria for the Evaluation of Music" (see above, p. 216), Dahlhaus suggests that composers in the later nineteenth century devised two different methods of generating large structures from such drastically reduced thematic material. Liszt and Wagner adopted the technique of real, or literal, sequence, by which ideas are not "developed," not pulled apart and reshaped (as in the Schoenberg model sentences), but are repeated more or less exactly at different pitch levels. Real sequence is "a means of elaborating a musical idea which in itself-like the Yearning motive from Tristan-needs no continuation and would not tolerate conventional 'rounding-off' in a closed period" (p. 46).

The alternative principle was provided by Brahms, who, "faced like them [Wagner and Liszt] with the difficulties caused by the concision of the basic thematic substance under the pressure of the all-pervading insistence on originality, sought a different solution in the procedure that Schoenberg was to call 'developing variation" " (pp. 47-48).

In the opening of Brahms's Piano Quartet in G Minor, op. 25, developing variation is used, Dahlhaus suggests, as "an expositional procedure ... in a formal function similar to that of modulatory sequence in Wagner and 
Liszt." Dahlhaus adopts Schoenberg's analytical methods to show how Brahms builds his first group from the continuous reinterpretation of two very brief motives, the $\mathrm{D}-\mathrm{B} b-\mathrm{F} \#-\mathrm{G}$ figure of $\mathrm{m} .1$ and the descending second of $\mathrm{m}$. 11 (see ex. 11), which are developed by such procedures as inversion, augmentation and diminution. ${ }^{18}$

As is often the case in his writing, Dahlhaus's dialectic (here between real sequences and developing variation) is provocative and illuminating. It cannot be taken quite literally: Liszt and Wagner (especially the latter) certainly use thematic development, and not just exact repetition, to build large structures. As Anthony Newcomb has recently shown, Act III, scene 1 of Siegfried unfolds in part as a progressive transformation and development of a brief motive. ${ }^{19}$ And even the later Brahms employs literal sequence on a large scale, as for example in the transition to the second subject in the first movement of the Third Symphony (mm. 15-31). But although the distinction Dahlhaus draws is too simple, there is no doubt that the kind of intense motivic processes he finds in op. 25, and that Schoenberg discovered in opp. 51 and 99, are more fundamental to Brahms's musical language than to Wagner's or Liszt's.

Like Schoenberg, Dahlhaus focuses on the construction of individual themes but does not, in his analyses, address broader formal issues. He boldly claims that for Brahms developing variation becomes the primary formal or "expositional" principle but fails to show just how such procedures might shape a large sonata-form movement (or even an entire exposition). Schoenberg too becomes less cogent on this subject. Indeed, his discussion of the standard instrumental forms, which occupies the last half of Fundamentals, lacks the imagination and conviction of the preceding chapters on theme construction. He divides sonata

\footnotetext{
${ }^{18}$ For further thematic-formal analysis of the Piano Quartet, op. 25, see below, p. 230. See also Frisch, Brahms's Sonata Structures, pp. 102-18, and James Webster, "Schubert's Sonata Form and Brahms's First Maturity," this journal 3 (1979), 62-65.

${ }^{19}$ See Anthony Newcomb, "The Birth of Music out of the Spirit of Drama," this journal 5 (1981), 58-64.
}

form into its traditional component sections and subsections-the exposition, for example, with a first group, transition, second group and codetta. But instead of specific compositional techniques Schoenberg provides us only with the information that the sonata form's

greatest merit ... is its extraordinary flexibility in accommodating the widest variety of musical ideas, long or short, many or few, active or passive, in almost any combination. The internal details may be subjected to almost any mutation without disturbing the aesthetic validity of the structure as a whole. ${ }^{20}$

A number of critics have, however, attempted to account for the whole structure, or at least for the crucial expositional part of it. I shall now examine how four of these writers relate developing variation to the larger dimension of Brahms's sonata forms.

\section{IV}

In an important early (1965) monograph on Brahms's D-Minor Piano Concerto, op. 15, Dahlhaus himself has shown how developing variation-defined somewhat differentlyprofoundly affects Brahms's treatment of sonata form. He observes that the themes of the first movement are arranged in distinct clusters, six in the double exposition, one in the development section, and four in the recapitulation and coda. ${ }^{21}$ Reaching across the "groups," Dahlhaus says, is a process of development, a high-level developing variation, by which Brahms constantly alters his theme. This process tends to supersede-or at least to overshadow-the traditional functions and divisions of sonata form. The technique of developing variation is not restricted to the development section, but extends into the exposition and recapitulation as well. "Brahms continually presents the main theme in different shapes, without ever going back to an ear-

\footnotetext{
${ }^{20}$ Schoenberg, Fundamentals, p. 200. The editor of Fundamentals, Gerald Strang, notes in his Preface that Schoenberg's chapter on Sonata-Allegro Form (XX) - the last in the book-"was incomplete and required reorganization" for publication (p. xiii). It is perhaps not surprising, then, that this chapter is one of the least successful in the book. ${ }^{21}$ Carl Dahlhaus, Johannes Brahms: Klavierkonzert nr. 1, d-moll, op. 15. Meisterwerke der Musik 3 (Munich, 1965), 9-10.
}

WALTER FRISCH Brahms and Developing Variation 
lier version where, according to the scheme of sonata form, we would expect him to-in the solo-exposition or in the reprise. The 'plastic' element of the grouping and the 'logical' element of continuing [fortschreitenden] variation support each other mutually" (p. 15).

Dahlhaus demonstrates how Brahms continually refashions his main theme by "singling out" and elaborating "its individual elements [Teilmomente]." At its second appearance $(\mathrm{m} .66)$ the theme is abbreviated and treated in canon-a device suggested by the imitation in its original statement $/ \mathrm{mm}$. 1518). In the solo exposition (m. 110) Brahms exploits another element, the chromatically descending bass-line first heard on a large scale in $\mathrm{mm} .1-25$. The recapitulation $(\mathrm{m} .310)$ constitutes perhaps the most astonishing development: here the Hauptthema returns above the initial $\mathrm{D}$ pedal but outlines a completely different harmony, an $\mathrm{E}$ dominantseventh rather than the original $\mathrm{B} b_{5}^{6}$.

The kind of developing variation that Dahlhaus adumbrates here differs from the procedure outlined by Schoenberg, or by Dahlhaus himself in the "Issues" essay. For he finds in the D-Minor Concerto not the continuous modification of small motive forms but the higher-level reinterpretation of a theme at each of its appearances in the sonata form. This is indeed one of Brahms's most characteristic and powerful techniques /although one that does not differ greatly from the procedures of the Viennese classicists, Haydn, Mozart, Beethoven, and Schubert, who also altered thematic returns in their sonata structures). There is much to be learned about Brahms's treatment of sonata form by examining especially the different ways he approaches the most critical moment of reinterpretation, the recapitulation.

One of the first writers to demonstrate a more continuous kind of developing variation at work on a higher level of the sonata structure was Rudolph Réti, in his important book The Thematic Process in Music (New York, 1951). Although Réti does not acknowledge any debt to the Schoenberg theoretical tradition (in fact he eschews altogether a bibliography or any reference to other theorists), his analytical approach to common-practice music strikingly recalls that of Schoenberg, whom he had in fact known personally in Europe during the earlier part of this century. ${ }^{22}$

"Thematic transformation" is Réti's equivalent for Schoenberg's developing variation land an equally unfortunate term, since it is too easily confused with specific romantic procedures of Schubert, Berlioz, Liszt, and the young Brahms). Réti devotes an entire chapter (Chapter 4) to detailing how the elements of a theme may be transformed. Among his classifications are not only the common devices of inversion and retrograde, and change of tempo or rhythm, but also more elaborate procedures such as "thematic compression" and the "thinning" and "filling" of thematic shapes. Several of these categories correspond quite closely to Schoenberg's "developing variations" of the broken-chord motive (see above, ex. 5).

Réti gives a persuasive demonstration of how the first movement of Mozart's G-Minor Symphony unfolds by a continuous kind of thematic transformation, by which the two basic motives of the main theme evolve throughout the exposition (pp. 137-39). But Brahms's art eludes Réti, because he seems obsessed to relate every theme of a piece to every other. For example, Brahms is said to derive each idea in the first movement of his Second Symphony from the motive forms of the opening theme (p. 81). Such a procedure is not unlikely in a mature Brahms work, and has, in fact, been sensitively demonstrated in that very piece, by David Epstein. ${ }^{23}$ But Réti isolates pitches with an alarming arbitrariness-with little regard for their rhythmic position in the measure, structural status, or harmonic importance. "If we single out certain notes of the new theme [m. 44], the first theme comes to the fore," he writes. "If we single out others, the second theme [m. 102] appears" (p. 81). Réti's examples simply relegate to small

\footnotetext{
${ }^{22}$ For the contacts between Réti and Schoenberg, see $\mathrm{H}$. $\mathrm{H}$. Stuckenschmidt, Schoenberg: His Life and Work, trans. Humphrey Searle (London, 1977), pp. 179, 183, 263. As a pianist and writer, Réti was an early and ardent champion of Schoenberg's atonal works. For the text of a letter of appreciation Schoenberg wrote to Réti in 1911, see Réti, Tonality, Atonality, Pantonality (London, 1958), pp. 48-49. ${ }^{23}$ See Epstein, Beyond Orpheus, pp. 162-77.
} 
print the notes which do not fit the shape he is trying to construe.

Besides distorting the themes, Réti tends to view them in relative isolation. His disconnected view of "thematic transformation" fails to account for the fluid continuity of Brahms's movement. His approach is thus less dynamic than Schoenberg's (or Epstein's); comparisons between the characteristics of individual themes treat the compositional procedure from above, rather than from within. ${ }^{24}$

At about the same time that Réti published his book in the United States, Arno Mitschka at Mainz completed an Inaugural-Dissertation that uncovers similar motivic evolution in Brahms. Mitschka's study of Brahms's sonata forms is undoubtedly the most perceptive large-scale treatment of the subject to date. ${ }^{25}$ His chapter headings (Hauptthema, Seitensatz, etc.) suggest a rather schematic approach, but in fact one of Mitschka's chief concerns is to show how Brahms creates thematic continuity across broad segments of the sonata structure. To describe this process he actually reinvents Schoenberg's concept of developing variation. Like Réti, Mitschka was apparently unfamiliar with Schoenberg's theories but came independently to the same view of compositional procedure.

Mitschka finds that Brahms's sonata forms cohere by a careful balance, a Gleichgewicht, between "striving and restraining forces" (p. 321). The result is a "static architecture" which maintains a tension between "the rush of development" and "the risk of disintegrating into small, lyrically rounded units" (p. 316).

\footnotetext{
${ }^{24}$ Réti's analyses have drawn fire from a number of prominent commentators, including Charles Rosen, The Classical Style (New York, 1971), p. 41; Leonard Meyer, Explaining Music (Berkeley and Los Angeles, 1973), pp. 59-67; and Epstein, Beyond Orpheus, p. 10.

${ }^{25}$ Der Sonatensatz in den Werken Johannes Brahms (Gütersloh, 1961). For other valuable studies of Brahms's sonata forms, see Viktor Urbantschitsch, "Die Entwicklung der Sonatenform bei Brahms," Studien zur Musikwissenschaft 14 (1927), 265-85; Edwin von der Nüll, "Strukturelle Grundbedingungen der Brahmsschen Sonatenexposition im Vergleich zur Klassik," Die Musik 22 (1939), 32-37; Robert Pascall, "Some Special Uses of Sonata Form by Brahms," Soundings 4 (1974), 58-63; and James Webster, "Schubert's Sonata Form and Brahms's First Maturity (II)" (see fn. 18).
}

The tension (Dahlhaus's logical-plastic dialectic) is manifest in one of Brahms's most important compositional principles, Ausdrückskontrast, or the juxtaposition of passages of widely divergent mood and character (pp. $30 \mathrm{ff}$ ).

How is Brahms able to avoid the closure that such themes can imply? According to Mitschka, "In the systematic development and concentration of expressive contrast from one part of the movement to another there is a further means of limiting the inclusion of lyricism in the sonata form: in several movements Brahms employs varying development" (p. 315). Ironically, Mitschka has coined a term, variierenden Entwicklung, that is the exact inverse of Schoenberg's developing variation.

Mitschka demonstrates how variierenden Entwicklung shapes the sonata structures of three Brahms works-the F-Minor Sonata, op. 5, the F-Minor Piano Quintet, op. 34, and the E-Minor Cello Sonata, op. 38. In the Piano Sonata all the themes of the first movement take shape through a "progressive transformation of the head motive" (p. 31). Similarly, all themes of the Cello Sonata are "expressive variants" of the main theme's head motive: "from the material of this widely oscillating theme different elements are developed one after another" (pp. 98-99). And in the Piano Quintet, Mitschka observes,

The basic elements of the main theme continually appear in altered form and with different expressive content; they comprise the leap of a fourth followed by an upward second and a triadic figure. ... All the motivic-thematic shapes are part of a developmental chain [Entwicklungskette] that leads first away from the head motive and then back again. This developmental process, however, condenses into individually molded thematic shapes, which contrast with each other in character and affective content (pp. 97-98).

Thus for Mitschka, as for Réti, developing variation becomes a dynamic process which shapes the outer form of a sonata structure.

Given Mitschka's evident sensitivity and articulateness, it seems odd that he intentionally restricts his commentary to these three relatively early works, claiming that after them Brahms virtually abandons the procedure of variierenden Entwicklung. "Brahms never
WALTER FRISCH Brahms and Developing

Variation 
again used the variation principle as clearly," he remarks. "The expositions of opp. 5, 34, and 38 must be viewed as shapes unfolding sui generis according to the principle of varying development" (pp. 99-100). Unique they may be-just as any work by a great composer has its own character-but they constitute just three of many pieces Brahms constructed by developing variation. Mitschka defines (or applies) the principle too narrowly; for as we have seen, it is a highly flexible structural tool that can operate on different levels (the phrase, the theme, the "group," the exposition) and in different dimensions (pitch, meter). Furthermore, it seems unlikely that a composer would refine a technique to as high a degree as Brahms had developing variation in the Piano Quintet, and then renounce it entirely. At any rate, the history of music includes few such instances /with the notable exception of Richard Strauss).

In fact, Klaus Velten has recently (1976) shown how the very same kind of developing variation that Mitschka discusses-the "progressive transformation of the head motive" - shapes the entire exposition of Brahms's G-Minor Piano Quartet, op. 25.26 Unlike Réti and Mitschka, Velten comes directly from the Schoenberg-Dahlhaus theoretical tradition. Indeed, the principal topic of his book is what Schoenberg's orchestration of op. 25 reveals about the music and about his relationship to Brahms. Velten precedes that discussion with a close analysis of how Brahms builds the massive exposition of op. 25 from continuous variation of one tiny motivic kernel, the interval of a minor second.

Velten parses the main theme differently from Dahlhaus, finding the basic motive presented twice in the opening measures-in ascending $(F \sharp-G, m .1)$ and descending $\left(E_{b}-D, m\right.$. 2) forms. Velten then charts an elaborate $A b$ leitungsreihe, a chain of derivations in which every successive theme or transitional idea grows from one of these two motive forms (pp. 66-74). (To Velten, then, the $\mathrm{B} b$ theme at $\mathrm{m} .11$ constitutes a development of the downward

${ }^{26}$ Klaus Velten, Schönbergs Instrumentation Bachscher und Brahmsscher Werke als Dokumente seines Traditionsverständnisses (Regensburg, 1976). form rather than a separate idea, as Dahlhaus has it.) Velten also suggests that the prevailing direction of the basic interval in a theme gives the exposition an ebb and flow of tension, an alternation between "rising" and "falling powers."

The second group of op. 25 comprises a virtual parade of large, well-profiled themes (four in all). Velten argues that this succession appears as "the goal of the preceding development," thereby fulfilling the motive's implications. The relation of developing variation to the formal structure thus becomes clear:

Since the second group is developed from the main theme, we understand that Brahms is using the principle of developing variation .... in the service of creating the form. The transformational process of the basic motive and its derivations finds its goal in the arrangement of the second group. The series of periodically constructed themes expresses the striving for a clear syntax. ... In the different themes Brahms repeatedly confirms the attained goal (p. 74).

Like Réti (whose work he does not seem to know) Velten regards the sonata exposition as a largely thematic process in which motives evolve toward a goal; the "form" represents the outward expression of that process. But Velten also shares an unfortunate Rétian tendency to distort the music to fit his theory: he seems obsessed with tracing every available Sekundschritt back to the basic motive.

Velten's analyses seem less considered, less sensitive to genuine compositional issues, than Schoenberg's in "Brahms the Progressive." He tends to leave rhythm and meter out of account. And to Velten's claim that the pervasive half-steps provide musical coherence, one is tempted to object (like Schoenberg's imagined skeptic): minor seconds can be found in almost any theme.

\section{$\mathrm{V}$}

Whatever their differences, the writers examined here share a belief that Brahms's music unfolds by a unique and characteristic process of continuous motivic/thematic development. Although several fail to acknowledge Schoenberg's authority, they all present analytical viewpoints or methodologies that have found their most powerful expression in Schoenberg's concept of developing variation. But what of 
the one figure whose authority has not been invoked at all?

In conclusion we might do well to let the composer himself speak. Of course, the intentional fallacy bids us beware of an artist's explanation of his own work: such testimony is not necessarily relevant or illuminating. With Brahms we need not worry too much, for he was notoriously unforthcoming about most personal subjects, including his own creative processes. ${ }^{27}$ On one or two occasions, however, he let slip utterances that are both revealing and directly relevant to our investigation.

Once Brahms responded to a rather superficial Réti-like thematic analysis of the German Requiem. In 1869 the critic Adolf Schubring, a good friend of Brahms, wrote an article in the Allgemeine Musikalische Zeitung that sought to demonstrate thematic unity in the third movement, "Herr, lehre doch mich." "All the melodies," Schubring claimed,

are derived by inversion, diminution, by the addition of prefixes and suffixes, from the following three main themes, which are themselves conceived in triple counterpoint:

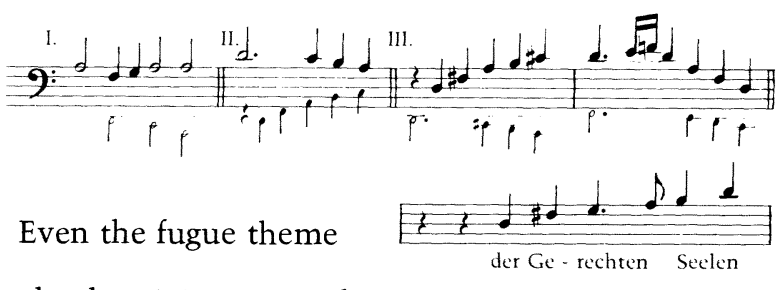

clearly originates in Theme III. ${ }^{28}$

Schubring's fragmentary example is neither easy to decipher, nor to locate in the actual

\footnotetext{
${ }^{27}$ For two good accounts in English of Brahms's inscrutable character and of his attitudes about the creative process, see Karl Geiringer, Brahms, 2nd edn. (New York, 1961) Chapter 22; and Hans Gal, Johannes Brahms: His Work and Personality, trans. Joseph Stein (New York, 1963), especially "Secrets of the Workshop." See also Donald M. McCorkle, "Five Fundamental Obstacles in Brahms Source Research," Acta Musicologica 48 (1976), especially pp. 256-58.

28"Sämmtliche Melodien ... sind aus folgenden im dreifachen Contrapunkte erfundenen Hauptthemen durch Umkehrung, Diminution, Vor- und Nach-Zusätze, u.s.w. entstanden.... Sogar das Fugen-Thema lässt deutlich seinen Ursprung aus Thema III erkennen." Adolf Schubring, "Schumanniana Nr. 12: Ein Deutsches Requiem .. . von Johannes Brahms," [Leipziger] Allgemeine Musikalische Zeitung 4 (1869), 10.
}

music. Theme I evidently refers to $\mathrm{mm}$. 3-4, and Theme II to $\mathrm{m}$. 105, although in the score the ascending part appears (in flutes and oboes) above the descending figure. Theme III seems to be just a different representation (and continuation) of the same measure; it appears nowhere in the movement as Schubring quotes it. Schubring's example displays, of course, no "triple counterpoint," only combinations of two themes.

Brahms did not pick apart Schubring's analysis in this way. Rather he found fault with its basic premise. He wrote to his friend:

I disagree that in the third movement the themes of the different sections have something in common. (Except for the small motive . $_{\text {. }} \delta_{\text {.) }}$ If it is nevertheless so-I deliberately call back nothing from my memory-I want no praise for it, but do confess that when I am working, my thoughts do not fly far enough away, and thus unintentionally come back, often with the same ideas. ${ }^{29}$

Brahms thus admits that in spite of himself, in spite of his conscious compositional process, the different thematic ideas might in the end be closely related. But he goe:; on to add that if he does want a relationship to be heard, he will ensure it: "Yet if I want to retain the same idea, then it should be clearly recognized in each transformation, augmentation, inversion. The other way would be a trivial game and always a sign of the most impoverished invention."

Neither Schubring's analysis nor Brahms's response has ever been commented on before, to my knowledge /although Brahms's succeeding remarks in the same letter on the art of writing variations on a theme have often been cited). But together they offer what is surely one of the most penetrating glimpses available into Brahms's workshop. Even so meticulous

\footnotetext{
29"IIch streite, dass in Nr. 3 die Themen der verschiedenen Sätze etwas miteinander gemein haben sollen. (Ausgenommen das kleine Motive ...) Ist es doch so (ich rufe mir absichtlich nichts ins Gedächtnis zurück): So will ich kein Lob dafür, sondern bekennen, dass meine Gedanken beim Arbeiten nich weit genug fliegen, also unabsichtlich öfter mit demselben zurückkommen." Iohannes Brahms Briefe an ... Adolf Schubring (Brahms Briefwechsel VIII), ed. Max Kalbeck (Berlin, 1915), p. 216

${ }^{30 \prime \prime}$ Will ich jedoch dieselbe Idee beibehalten, so soll man sie schon in jeder Verwandlung, Vergrosserung, Umkehrung, deutlich erkennen. Das andere wäre schlimme Spielerei und immer ein Zeichen armseligster Erfindung."
}

WALTER FRISCH Brahms and Developing Variation 
and disciplined a composer as he acknowledges that the unconscious can play a large role in the creative process. He grants, in effect, that the procedures of developing variationthe continuous reinterpretation of basic material-can operate without his awareness to create valid thematic relationships. Indeed, Schubring's analysis, although shallow, is essentially accurate: the different themes of the German Requiem movement do seem closely related. Certainly there is more coherence than that provided by the d. Ad figure, the only common denominator which Brahms says he intended.

On another occasion Brahms spoke again about the roles of the conscious and unconscious in his creative process. And here he seems to say that both forces operate by a procedure very much like developing variation, generating a work from a single thematic kernel. In a journal kept during his acquaintance with Brahms, George Henschel notes that the composer said to him one day:

There is no real creating without hard work. That which you would call invention, that is to say, a thought, an idea, is simply an inspiration from above, for which I am not responsible, which is no merit of mine. Yea, it is a present, a gift, which I ought even to despise until I have made it my own by right of hard work. And there need be no hurry about that, either. It is as with the seed-corn; it germinates unconsciously and in spite of ourselves. When I, for instance, have found the first phrase of a song, say,

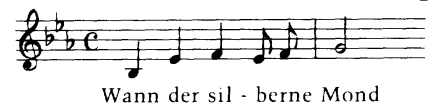

I might shut the book there and then go for a walk, do some other work, and perhaps not think of it again for months. Nothing, however, is lost. If afterward I approach the subject again, it is sure to have taken shape: I can now begin to really work at it. $^{31}$

For Brahms, then, composition begins with the "gift" of a musical idea, which proceeds to grow and expand almost of its own accord. Then, in a separate and conscious process, the composer draws all the implications and pos-

${ }^{31}$ George Henschel, Personal Recollections of Johannes Brahms (Boston, 1907), pp. 22-23. The song quoted is, of course, "Die Mainacht," op. 43, no. 2. For an analysis of how the procedures of developing variation shape this song, see Frisch, Brahms's Sonata Structures, pp. 179-87. sibilities out of that single idea: "nothing is lost." ${ }^{\prime 32}$

And what of the outward form that such a process creates? It is a pity that Brahms left behind no specific accounts of how he approached his beloved sonata form. We do, however, have the valuable testimony of Gustav Jenner, who studied composition with Brahms in 1888 . Brahms told Jenner to study the sonata forms of Beethoven, paying particular attention to the influence of Beethoven's themes on the design of the movements; he also encouraged Jenner to compare Beethoven's music with Schubert's in this regard. ${ }^{33}$ From Brahms Jenner learned that a sonata structure must grow logically from a theme: "One has not written a sonata if he holds together a few ideas merely with the outward form of a sonata; on the contrary, the sonata form must of necessity result from the idea." ${ }^{\prime 34}$ What mattered to Brahms, Jenner reports, was the spirit, not the schema, of sonata form.

As in the Henschel quotation, Brahms emphasizes the importance of the basic "idea" as progenitor of the outward form. With such statements as these we seem to have come full circle, back to Schoenberg's polemical /and organic) formulation of developing variation as the basis of real composition, in which there "is nothing but the endless reshaping of a basic shape." We also see Brahms openly espousing a compositional aesthetic that Dahlhaus claims as characteristic of the later nineteenth century: musical form becomes dependent on, and consequent to, the initial idea. But Brahms's is no weak dependence. For in his best music the form becomes a luminous expression of the flexible, powerful procedures of developing variation.

\footnotetext{
${ }^{32}$ There are striking resemblances to the Henschel quotation in three other reported statements by Brahms on his creative process. They use either the seedcorn metaphor or the idea of going out for a walk (a very Beethovenian one), or both. See the comment to Simrock cited in Max Kalbeck, Johannes Brahms, rev. edn. (Berlin, 1921), II, 182; the remark quoted by Gustav Jenner, Johannes Brahms als Mensch, Lehrer und Künstler (Marburg, 1905), p. 42; and the conversation between Brahms and Arthur Abell, given in Robert H. Schauffler, The Unknown Brahms (New York, 1933|, pp. 177-79.

${ }^{33}$ Jenner, p. 60.

${ }^{34}$ Ibid., p. 6.
} 